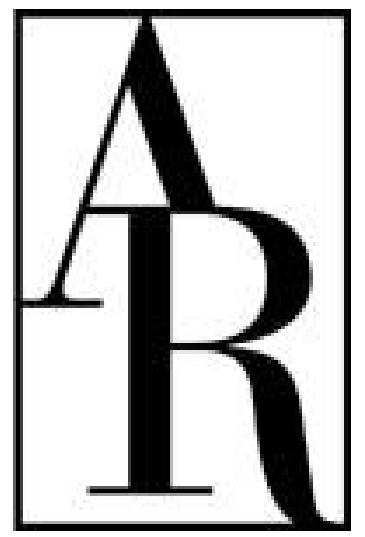

The Individual Voice in Language

Author(s): Barbara Johnstone

Source: Annual Review of Anthropology, Vol. 29 (2000), pp. 405-424

Published by: Annual Reviews

Stable URL: http://www.jstor.org/stable/223426

Accessed: 08/02/2010 10:48

Your use of the JSTOR archive indicates your acceptance of JSTOR's Terms and Conditions of Use, available at http://www.jstor.org/page/info/about/policies/terms.jsp. JSTOR's Terms and Conditions of Use provides, in part, that unless you have obtained prior permission, you may not download an entire issue of a journal or multiple copies of articles, and you may use content in the JSTOR archive only for your personal, non-commercial use.

Please contact the publisher regarding any further use of this work. Publisher contact information may be obtained at http://www.jstor.org/action/showPublisher?publisherCode=annrevs.

Each copy of any part of a JSTOR transmission must contain the same copyright notice that appears on the screen or printed page of such transmission.

JSTOR is a not-for-profit service that helps scholars, researchers, and students discover, use, and build upon a wide range of content in a trusted digital archive. We use information technology and tools to increase productivity and facilitate new forms of scholarship. For more information about JSTOR, please contact support@jstor.org.

Annual Reviews is collaborating with JSTOR to digitize, preserve and extend access to Annual Review of Anthropology. 


\title{
The Individual Voice in Language
}

\author{
Barbara Johnstone \\ Department of English, Carnegie Mellon University, Pittsburgh, \\ Pennsylvania 15213-3890; e-mail: bj4@andrew.cmu.edu
}

\begin{abstract}
Key Words individuality, self-expression, linguistic theory, sociolinguistics, pragmatics
\end{abstract}

- Abstract This article presents arguments for supplementing linguistic work focused on abstract social systems (languages, dialects, varieties) with linguistic work focused on individual speakers. It begins by reviewing how the individual speaker has been conceived of (when at all) in linguistics and linguistic anthropology. Two areas of linguistic research, discourse processing and linguistic variation and change, serve as examples of what is to be gained by supplementing a linguistics of systems with a linguistics of speakers. Finally, interest in the individual voice is placed in the context of a larger shift toward a more phenomenological approach to language and greater particularity in methods for its study.

\section{INTRODUCTION}

Many anthropologists and linguists, together with other humanists and social scientists, have begun to pay renewed critical attention to the roles of particular human beings in human activities. Old questions are being asked again, and new ones raised, about such concepts as the self, self-consciousness, subjectivity, individuality and individual identity, voice, and agency. Among the many issues being considered is that of the relationships between "speakers," "discourse," and "language." Much of the discussion about these relationships during the past several decades has focused on the ways in which the notion of "speaker" can be shown to be historically and culturally contingent. (I adopt the convention here of using "speaker" for anyone who speaks, signs, writes, or uses some other medium for language.) This discussion has challenged the once conventional view that speakers are naturally and completely in control of their utterances. In this traditional view, speakers choose what to say, how to say it, and what it means. A "voice," in this view, is a strategically adopted way of sounding that a speaker designs and modifies as a result of analyzing the rhetorical or aesthetic task at hand. In this conventional view, the issue of how speakers "project themselves into discourse" (Cherry 1998) arises only in the context of relatively overt strategic choices in relatively planned discourse. 
Rhetorical ethos (see Ross 1924, BkI Ch 2) or the persuasive presentation of a rhetor's moral character, comes about through the deployment of carefully considered tactics for calling attention to one's best features. A literary persona or an "implied author" (Booth 1961) is seen as resulting from the purposeful adoption of a carefully chosen set of characteristics of rhetorical stance and linguistic style.

This conventional view has been called into question in several ways. The takenfor-granted notion of the autonomous, agentive speaking self has been challenged by historians, such as Stephen Greenblatt (1980) and Colin Morris (1987), and philosophers, such as Charles Taylor (1989), who describe the historical contexts in which particular Western ways of imagining individual identity have arisen. The traditional view has also been relativized through ethnographic work (Mauss 1985, Rosaldo 1984, Carrithers et al 1985) showing that there are people whose talk and other actions suggest that they do not share the Western notion of the self. Challenges to the traditional notion of the linguistic individual from literary theory point out that the speaking self has to be imagined differently from genre to genre. Mikhael Bakhtin $(1981,1986)$ showed, for example, that the novel is fundamentally "heteroglossic" or multi-voiced; James Goodwin (1993) suggests that individuality became easier to think about as autobiography became more possible to write and read.

These challenges lead to questions about when, how, and why individual speakers are connected with discourse and language in particular historical, cultural, and generic contexts. Answering such questions requires studying and describing varying ideologies about how individuality, idiosyncracy, personhood, authorship, self-expression, and agency are imagined, evaluated, and talked about. Alessandro Duranti (1993), among others (Rosen 1995), points out the conventional idea that meaning resides in the speaker, and that interpretation is thus a process of correctly recovering a speaker's intentions, is rooted in a characteristically Western way of attributing internal mental states to others. It has been repeatedly observed that audiences are always in one way or another "coauthors" (Duranti \& Brenneis 1986), sometimes contributing to the construction of form (Goodwin 1979, Ferrara 1992), sometimes to the determination of meaning (Ochs et al 1979, Brenneis 1986). Responsibility for the evidential adequacy of an utterance and for its meaning and its illocutionary and perlocutionary effects can also be shared among interlocutors, in various ways, depending on the context and the activity at hand (Hill \& Irvine 1992). As Goffman showed (1981), speakers may stand in several sometimes overlapping "footings" with regard to their discourse: The "animator" or physical producer of a string of words may or may not also be their "author," the person who composed them, or their "principal," the person who is responsible for their force.

In this essay I take a different approach. I am interested not in exploring differences in how speakers are connected to discourse and language in different ideological and material contexts (which can indeed vary widely, with diverse consequences), but in thinking about how speakers are always necessarily connected 
to discourse and language. I ask, in other words, what it is about language, about human beings, and about human interaction that connects particular individual human beings with particular utterances and ways of speaking and thinking? The result of this inquiry is to encourage us to rethink a number of other basic notions, including the notion of "language" and the role of the study of discourse in linguistics.

Although ideological individualism - the valuation of individuality and its expression-is by no means universal, human individuality is a prerequisite for humanity. Self-awareness - a sense of oneself as physically discrete, autonomous, and temporally continuous - is crucial for the maintenance of social life (Hallowell 1955). Culture provides humans with various ways of orienting themselves as individuals, including ways of identifying themselves and others (such as names and terms for relationships), ways of evaluating themselves and their actions, and ways of displaying the continuity of their memories and physical beings, such as narrative (Carr 1986, Linde 1993). The French linguist Émile Benveniste (1986) argued, in fact, that it is precisely language that creates the human experience of individuality: Language makes subjectivity possible via universal systems of grammatical person, which force us to categorize the world into self and others. Through talk and other aspects of behavior, individuals display their individuality. In other words, people express their individuality with everything they do, whether or not self-expression is at the moment or in the context particularly valued or even considered to be relevant. When people understand each other fairly easily it is because, for the most part, it is more practical to use familiar sounds, words, and syntactic patterns than to use unfamiliar ones that would require more interpretive work. People recognize each other as individuals, however, because each person has a unique set of linguistic resources on which to draw, and each person makes unique, creative uses of these resources.

Most scholarship bearing explicitly on the linguistic individual in this sense comes from literary study and rhetorical criticism, and the individual voices in question are those of particular poets, storytellers, and orators. I do not review this literature here, although the suggestions I make later about the need for closer stylistic and rhetorical analyses of individual texts draw on ideas and analytical techniques from rhetoric and literary theory. Because there is not a coherent body of work in linguistics or linguistic anthropology that is specifically about the individual in language, and because there is so much work that is potentially relevant, this review has to be selective. I begin by briefly tracing how the idea of the linguistic individual enters into linguistic theory. I then talk about two large issues that concern students of language: the nature of grammar and where it is located, and linguistic variation and its relationship to language change. Finally, I show how renewed interest in the individual voice is part of a larger shift in linguistics toward a more phenomenological approach to language and toward greater methodological particularity in its study. 


\section{THE INDIVIDUAL IN LINGUISTIC THEORY}

For the most part, linguists make statements about languages rather than about speakers, conceptualizing their object of study in such a way as to exclude from consideration individual voices and individuals' choices. The idea that language is best seen as an abstract system, located in the social realm, has its roots in the foundational texts of twentieth-century structuralism. Under the sway of Ferdinand de Saussure's (1966) distinction between langue (the abstract system that Saussure saw as the object of study for linguistics) and parole (actual instances of discourse), linguists attempting to provide formal models of linguistic competence usually ignore individual differences. Possibly influenced by Emile Durkheim's social realism (Holdcroft 1991:143-55), Saussure repeatedly described language as "a social fact" that is not reducible to an aggregate of individual utterances. Although discourse (speech or parole) "has both an individual and a social side" (Saussure 1966:8), langue "exists only by virtue of a sort of contract signed by members of a community" (p. 14). For Saussure, "[1]anguage exists in the form of a sum of impressions deposited in the brain of each member of a community, almost like a dictionary of which identical copies have been distributed to each individual. Language exists in each individual, yet is common to all" (1966:19).

Linguists who study langue thus study something that is by definition superindividual, located in individuals only the way a piece of software may be installed on multiple computers. The object of study for structuralist linguistics is a "shared" system, that is a system that is of interest only insofar as it can be treated as identical from individual to individual. Structuralist linguists study such abstract entities as dialects, varieties, languages and, in some cases and secondarily, the social groups that are sometimes associated with these entities. Languages, dialects, and varieties are sometimes treated not as convenient abstractions but as real objects, which can even be referred to as agents: Languages drop pronouns, for example, sounds shift around in phonemic systems, and dialects influence other dialects. In the structuralist view, there are two ways of handling variation in linguistic knowledge from individual to individual within a speech community. One is to handle idiosyncracy as evidence of social or cognitive deviance. The other is to see a linguistic individual as constituted by the set of selections he or she makes from a large but closed set of conventional ways of creating meaning. In this latter view, individual uniqueness is an artifact of the infinitude of possibilities provided by the fact that some of the rules of language can be applied an infinite number of times, so that although the number of rules needed to characterize a speaker's knowledge is finite, the number of utterances that can result from these rules is infinite. (This is what it means in generative theory to say that speakers are fundamentally creative; "creative" here means something quite different than in nontechnical usage.) Because it is theoretically impossible to study the individual in the linguistics of langue, studies in this framework that purport to 
examine individual variation invariably turn out to be studies of the "shared" linguistic competence of groups, albeit sometimes relatively small ones. Historically, structuralist linguistics is partly rooted in the nineteenth-century politics. The ideology of nationalism depended on the notion of the autonomous, super-individual language because a nation was defined, in part, linguistically. Arguments in favor of the nation-states that replaced authoritarian feudal systems were often based on images of sharing: A nation consisted of people with a shared culture, a shared history, and a shared language.

Anyone who thinks about linguistic variation and change is forced, however, to confront questions about the relationships between individual speakers and languages. A change in the behavior of a group necessarily begins with an innovation by an individual, and the two perspectives engendered by this fact have always competed in the dialectological and sociolinguistic study of variation and change. Nineteenth-century neogrammarians such as Rasmus Rask and Jacob Grimm focused primarily on the ways in which linguistic systems evolve (one sound shift can lead to another by creating dysfunctional homophony, for example, or a morphological paradigm can be regularized via analogy), and contemporary variationist sociolinguistics continues to be primarily concerned with change in linguistic systems (Labov 1994). But there has always been an alternative perspective from which to view language change, that of the individual speaker. Hermann Paul (1889:xliii), for example, stressing the role of the individual in change, remarked that "every linguistic creation is always the work of one single individual only." Nineteenth-century comparative linguists of the "idealist" or "aesthetic" school such as Wilhelm von Humboldt (1971) and Karl Vossler (1904), asking the still troublesome "actuation question" about how changes in linguistic systems start, also focused on the fact that change necessarily begins in a single instance of innovation. For these linguists, such innovative acts were the result of creative aesthetic choices (sometimes by great authors) made in the expression of individual spirit or genius (Robins 1976:189-90). Although, as noted, contemporary theories of variation and change typically take the perspective of the group, there is increasing interest in the roles played by individuals, as we shall see.

Linguistic anthropologists such as Edward Sapir, Dell Hymes, and Paul Friedrich have repeatedly stressed the importance of approaching language from the perspective of the individual as well as the social. If one looks at culture from the perspective of a child, Sapir notes, one sees that each individual's culture must be different (1949:590-97). Sapir argued explicitly against social realism, pointing out repeatedly that languages and cultures were abstractions that could mislead: "In linguistics, abstracted speech sounds, words, and the arrangement of words have come to have so authentic a vitality that one can speak of 'regular sound change' and 'loss of genders' without knowing or caring who opened their mouths, at what time, to communicate what to whom" (p. 579). Individual behavior is always socially conditioned, "the complex resultant of an incredibly 
elaborate cultural history" (p. 572), but "conversely, no matter how rigorously necessary in practice the analyzed pattern may seem to be, it is always possible ... for the lone individual to effect a transformation of form or meaning which is capable of communication to other individuals" (pp. 572-73). As a result, the only way to come to a complete understanding of culture is through "a minute and sympathetic study of individual behavior ... in a state of society" (p. 576). Anthropologists who work with linguistic informants are regularly faced with individual style and idiosyncracy and are led to wonder in what sense an individual speaker can embody a language or represent its other speakers (Craig 1979, Coulmas 1981, Friedrich 1986). Dell Hymes in particular has taken up and expanded on Sapir's recurring interest in the linguistic individual. For Hymes, linguistic competence is "personal ability (not just grammatical knowledge, systemic potential of a grammar, superorganic property of a society, or, indeed, irrelevant to persons in any other way)" (Hymes 1974:206), and individual differences should be given "foundational status" as a "vantage point from which to consider questions of method and theory in the study of language in general" (1979:35).

Underlying the view that the study of language in general should start in the study of individual differences is the observation that language is fundamentally the property of the individual. This is true whether language is defined as competence (no two speakers have the same set of experiences from which to generalize, so no two speakers could possibly have exactly the same knowledge of language) or whether language is defined as discourse (even in settings in which ideological individualism does not play the role it does in Western societies, different people speak differently and say different things). Idiosyncracy in linguistic competence has long been an embarrassment in generative theory, particularly in its earlier, less abstract versions. Arguments about the nature of linguistic structure are based on claims about the possibility or impossibility, according to the "intuition" of a native speaker, of surface arrangements of elements. A fairly casual study of individual variation in such acceptability judgments was conducted by Ross (1979), who found that of 29 friends, no two made exactly the same judgments about a set of English constructions that had played key roles in syntactic argumentation. William Labov (1972:192-99) tested people's reactions to ambiguous sentences such as "[a]ll the circles don't have dots in them." Previous syntactic argumentation about this issue (Carden 1970) had suggested there should be two syntactic "dialects" with respect to such combinations of quantification and negation: Some speakers would interpret the sentence to mean that there were no circles with dots, and others would interpret it to mean that there were some with dots and some without. Labov found that any of the speakers he tested could produce either interpretation if the context was right. Other informal studies, as well as innumerable conversations among students of syntax about the differences between "my dialect" and yours when it comes to acceptability judgments, also suggest that there is actually little homogeneity in the syntactic intuitions that are used as evidence about the nature of linguistic competence. It should be noted, however, that the goal of generative theory is not to describe the behavior of 
actual speakers in heterogeneous speech communities (which is to say communities in which different people make different acceptability judgments), but rather to model the knowledge of an idealized speaker-hearer in an idealized homogeneous community in which everyone would make the same acceptability judgments. As a result, empirical findings of heterogeneity in linguistic intuitions bear only on certain forms of argumentation in generative theory, not on the enterprise as a whole.

The claim that nothing except innate predilections underlying human linguistic competence could be completely homogeneous from speaker to speaker is not, however, fundamentally an empirical claim. It is rather the logical consequence of the fact that each human's world of experience is different. Knowledge of language is fundamentally private and individual, and it is impossible that two people could do things with language the same way. This is the result of the fact that people are not born knowing how to talk. Although we say that many American children "learn English," in fact no two learn exactly the same thing. One person's language is different from another's because each individual has a different set of linguistic memories and each may make different generalizations on the basis of what he or she hears. This is obvious in the case of children, who have accumulated relatively few linguistic memories, and we regularly notice their idiosyncratic generalizations. But adults' generalizations are idiosyncratic, too, both in the sense that they may in fact be different from anyone else's generalizations and in the more fundamental sense that they are logically independent of anyone else's generalizations. It is often obvious that people have different vocabularies and their sense of the nuances of word meaning varies, but it is equally the case that people have different grammars. Universal grammatical predispositions may lead human beings to make certain kinds of generalizations about linguistic input and not others, but such predispositions do not fully determine exactly which generalizations a person will make. If two language-acquirers hear similar sounds and patterns, they may make similar generalizations, and if the generalizations are similar enough, the two may be able to understand each other (depending on what counts as understanding another person in the situation at hand). Thus, we may say that the two speak the same language or set of languages (depending on how "speaking a language" or "speaking the same language" is conceived of in the situation at hand).

If language is thought of as linguistic action rather than as linguistic competence, the argument that language is fundamentally individual is even easier to make. Certainly there are settings in which sounding different from other speakerssaying different things and saying them differently-is highly valued and settings in which it is less so. European-American society in the United States, with its often noted ideology of individualism in general, has provided many canonical public examples of linguistic individualism, as well as an articulated theory of "expressive individualism" (Bellah et al 1985, Hansen 1990) within which conscious efforts to use language in idiosyncratic ways are valued. For Ralph Waldo Emerson, for example, "the maker of a sentence ... launches out into the infinite and builds a road 
into Chaos and old Night, and is followed by those who hear him with something of wild, creative delight" (see Becker 1981). But even in settings in which sounding like others is stressed and sounding different is not, it is impossible to repeat every aspect of a linguistic act. In Bloch's (1971) terms, it is impossible to "speak the past" without bringing the past into the linguistic present: a present speaker, a present context, a present instance of the words. The words and phrases one uses can be conventional ones, but "every use of language is a fresh application, a metaphorical extension of existing systems, made at risk" (LePage \& TabouretKeller 1985:196).

\section{INDIVIDUALS AND DISCOURSE PROCESSES}

Thinking about language from the perspective of the individual means reexamining conventional wisdom about how utterances come to be and how they are interpreted. Most theories for thinking about the production of discourse make use of terms such as "rules," "conventions," or "constraints." According to such theories, when people act the same way other people do, whether in language or in other arenas of life, it is because they are acting in accordance with the same rules: A sentence, paragraph, or story seems well-formed and interpretable because its author knows the rules (conscious or not) that delimit what sentence-, paragraph-, or story-builders can do. The terms "rule," "convention," and "constraint" are used in various ways, and in different theoretical contexts they come with different sets of implications. For purposes of the current discussion, only one broad distinction needs to be drawn, however. The claim that someone is "following" a rule is sometimes understood as a claim about an actual mental process (Chomsky 1986:221-75). Rules in this sense are "generative" in the strict sense: Discourse is generated when speakers (or computer programs, which in this view operate the same way human speakers do) apply preexisting computational procedures to create utterances. (Chomsky uses the term "generative" slightly more loosely than this. For him, the best theory of language is one that models rules as causally related to utterances, and because there is no better way of resolving the issue of the role of rules in text building than the one proposed in the best theory of language, rules must be understood as causally related to utterances.) In this view, rules are "a priori” (Hopper 1988), existing before and apart from utterances. Text-building in general is implicitly analogized, in this view, with the sort of conscious, strategic, rule-based composition that is characteristic of traditional language instruction, in which constructing a sentence is, for example, a matter of selecting a meaning, then selecting the apppropriate grammatical subject, then selecting a predicate, then adjusting agreement markers, then perhaps reading it aloud.

Alternatively, the claim that a person is "following" a rule can be a way of stating a generalization about the person's behavior (Kripke 1982). It is possible to look at a transcript, corpus, or text and make statements about how 
it is structured "as a rule" without claiming that the "rules" one thereby formulates were actually causal in the process of text-building. Reference books about the grammars of languages are compendia of rules of this sort, formulated on the basis of examinations of actual discourse. Such statistical generalizations can only be formulated from a temporal distance, by looking back at what people have done in the past. If we take seriously the observation that language is fundamentally individual, rules must be seen in this way, as a posteriori generalizations about already-uttered discourse. In this view, discourse is not created or interpreted via the application of a priori rules. Instead, structure and meaning are "emergent" (Hopper 1988, Ochs et al 1996, Cumming \& Ono 1997), created in the process of interaction as people devise strategies for responding to ongoing situations and solving immediate communicative problems. Some of these strategies may be based on "grammar," if grammar is defined as individuals' retrospective statistical generalizations about discourse. Grammar functions, in this way of thinking, as a heuristic for linguistic invention, parallel to the classical topoi for the generation of rhetorical strategies (Ochs 1969, 1983; Young 1987; Enos \& Lauer 1992). But grammar is not the only strategy for text-building (Becker 1995). It is, for example, possible to communicate using whole unanalyzed chunks of language (Coulmas 1981, Tannen 1987) or to make oneself understood to people who do not understand one's language, which cannot be the result of grammar in any but an extremely abstract sense.

Theories of pragmatics typically describe the process of interpretation, too, as based in conventions shared by communities: People can interpret utterances if they can parse them into allowable patterns, if they have heard the same thing before, or if the utterances depart from familiar structures or formulas in conventional ways. But although conventionality is as crucial in interpretation as it is in text-building (we far more often decide what an utterance means with reference to conventions of structure and use than completely de novo), speakers can and do cope with linguistic novelty, for example in early childhood and in interlinguistic or intercultural communication. Any theory of pragmatics must at least suggest an explanation for the interpretation of linguistic newness. As Stephen Levinson (1983:17) points out, "[an] utterance may have no conventional meaning at all." Thinking about linguistic individuals means thinking about the interpretation of nonconventional ways of meaning and suggests the need for a pragmatics based on general cognitive principles, such as the relevance theory of Dan Sperber $\&$ Dierdre Wilson (1986), rather than on specific linguistic and cultural conventions. Such approaches treat the interpretation of newness and idiosyncracy as the model for interpretation in general, framing regularities in how people interpret speech as maxims or principles rather than rules and treating understanding as a hermeneutic, problem-solving procedure. For Leech (1983:21), for example, "general pragmatics is principle-controlled (rhetorical)." Although there are conventions that sometimes relate the sense of an utterance to its force, "the principles of pragmatics are fundamentally non-conventional" (Leech 1983:24). 


\section{THE SOCIOLINGUISTICS OF SPEAKERS}

Summarizing the goals of sociolinguistics, R. A. Hudson (1980:12) claims that "sociolinguists would agree that it is essential to keep the individual firmly in the centre of interest, and to avoid losing sight of him while talking about large-scale abstractions and movements." In practice, however, this has been the exception rather than the norm. Standard accounts of variation and change are framed on the abstract level of the dialect or the speech community. Only when an innovation has been partially or fully taken up by a socially delineated group of speakers is it handled as a change in progress, and the group is then identified with the new form. This point is made especially clearly by Labov (1972:277):

What is the origin of a linguistic change? Clearly not the act of some one individual whose tongue slips, or who slips into an odd habit of his own. We define language ... as an instrument used by the members of the community to communicate with one another. Idiosyncratic habits are not a part of language so conceived, and idiosyncratic changes no more so. Therefore we can say that the language has changed only when a group of speakers use a different pattern to communicate with each other... Let us assume that a certain word or pronunciation was indeed introduced by one individual. It becomes part of the language only when it is adopted by others, i.e., when it is propagated. Therefore the origin of a change $i$ its "propagation" or acceptance by others.

As James Milroy points out (1992:164-205) the "actuation problem"-how does linguistic change begin?- - has in fact been relatively little studied, because the linguistic system, not the individual speaker, is the focus of interest for Labovian sociolinguists, who are primarily interested in the mechanisms of change in language and only secondarily in how individuals' linguistic behavior is socially constrained. When variationist sociolinguists do talk about the relationship between "social characteristics" and individuals' behavior, individuals are operationalized as bundles of demographic facts, and an individual's linguistic behavior is sometimes implicitly seen as determined by these facts (Johnstone 1997). Women speak the way they do because they are women, working-class speakers because they are working-class, and so on. Correlation is treated, however unintentionally, as if it were causation; the actual mechanisms by which gender, class, and other aspects of identity are connected with linguistic behavior are not the focus of interest in any case, so the logical problem is rarely noticed.

Sociolinguistics has shared this way of accounting for the individual with other social science disciplines. Like the traditional sociolinguistic concept of dialect or variety as shared communicative resource, the traditional anthropological concept of culture as shared knowledge has the effect of creating imagined groups of nonindividuated others (Abu-Lughod 1991, Hannerz 1996). As Cohen (1994:6) points out, "Western social science proceeds from the top downwards, from society to 
the individual, deriving individuals from the social structures to which they belong: class, nationality, state, ethnic group, tribe, kinship group, gender, religion, caste, generation, and so on. We have concentrated on these collective structures and categories and by and large have taken the individual for granted." In thoroughgoing social realist approaches, self comes to be seen entirely as a cultural construct, and presentations of identity (Goffman 1959) are seen as dictated by the structure of the situation rather than by the creative imagination of a coherent self (Cohen 1993:204). Individuals are recognized only when they are exceptional, so that the opposite of "individuality" becomes "normality" (Cohen 1993:215).

Some sociolinguistic accounts of variation and change, in some cases taking their cue from work by linguistic anthropologists (Silverstein 1979, Kroskrity et al 1992, Gal 1993, Woolard \& Schieffelin 1994) supplement this social constructivist model of the individual with the observation that ideologies - beliefs about what social and linguistic facts mean-play a key mediating role between individual and language (Kroch \& Small 1978, Sankoff et al 1989, Milroy 1999). But social facts and linguistic facts, as well as ideologies and ways of speaking, are also mediated by individual speakers. The actual mechanisms by which variation comes to have meaning and patterns of language use come to change can only be seen in situated choices (often unconscious but sometimes not) by individuals creating unique ways to sound, to be, and to respond to specific rhetorical exigencies. Thus "system-oriented" approaches to variation must be supplemented with "speaker-oriented" approaches (Milroy 1992:164-205). Newer models of variation have moved toward providing ways of understanding variation from individual to individual, because sociolinguists are increasingly coming, once again, to see variability as a resource for the expression of an individual's identity and to see linguistic change, therefore, as potentially originating in expressions of identity. This, it should be noted, is a return to the approach originally taken by William Labov (1963) in the Martha's Vineyard study that initiated the sociolinguistic study of language change, in which the use of a centralized diphthong in words like house was shown to be correlated with particular facts about speakers' identities. In later work, however, Labov used less emic explanatory variables, such as socio-economic class (variably defined, but often in terms of income and occupation) and gender (defined in terms of dichotomous sex). Reviewing the shift back to more emic, locally relevant ways of thinking about what might trigger linguistic change and cause its spread, Lesley Milroy (1987:131-34) points out that social groups are more fluid than standard demographic characterizations of people require them to be, and people's speech less consistent over time and situation. Individuals show that they identify with different groups at different times by varying their speech. Milroy's work focuses on the effects on an individual's speech of the strength of his or her social ties to other people in the community; she finds that differences between individuals are better accounted for in terms of the nature and intensity of their relationships in the local community than in terms of social class or status. 
In relatively homogeneous societies with relatively clearly defined social norms and much contact among speakers, different people may be relatively likely to attribute the same symbolic meanings to linguistic choices. [As James Milroy (1992:95-109) points out particularly clearly, however, this does not imply that everyone in such a community will actually make the same choices; communities with tighter social ties between members may in fact display greater linguistic variation, so that the symbolic meanings of choices are frequently displayed and thereby enforced.] The people whose behavior is best accounted for in the Labovian model and in other theories in which the focus of study is the language, the dialect, or the variety are people in relatively homogeneous communities in which norms are widely shared. The setting in which such speakers are most likely to be found is a monolingual nation-state on the European model. As R. B. LePage \& Andrée Tabouret-Keller (1985) show, individuals' models of linguistic norms are less consistent in more heteroglot, culturally diverse settings, where people are less likely to project linguistic self-images similar to those of their neighbors.

If culturally fluid contact settings rather than relatively homogeneous nationstates are taken as the prototypical object of sociolinguistic inquiry, the locus of linguistic variation appears as the individual rather than the community. In work in the Caribbean, for example, LePage (1994:117) found "no other secure starting-point, no describable linguistic unit but our individual informants." Because different speakers used and defined their identities in terms of different combinations of languages and degrees of creolization, the research team found that their original plan of categorizing speakers or utterances into "variants of units within a communal language" would have led to "infinite regress." Seeing language as "essentially idiosyncratic," LePage \& Tabouret-Keller (1985:2) thus suggest a sociolinguistics of the individual. "Language," for them, is the linguistic repertoire of an individual, perhaps, under social conditions that promote "focusing," all drawn from one conventionally defined "language" such as French or Spanish, but perhaps not. Some speakers in any community may use language in relatively conventional ways that are easy to codify, whereas other speakers may be far more inventive and idiosyncratic. LePage \& Tabouret-Keller thus see the individual as "the locus of his language" (1985:116).

Nancy Dorian's (1994) study of "personal pattern variation" shows what can be gained methodologically from paying attention to linguistic individuals in sociolinguistic field research. Among Gaelic-speaking "fisherfolk" in three villages in East Sutherland, Scotland, there is considerable linguistic variation among people who are, according to the usual social parameters, the same: siblings, spouses, parents and their children, members of the same social networks, people the same age. Dorian points out that because sociolinguists are not forewarned about the possibility of this sort of variation, they may not notice it. In the East Sutherland communities, according to Dorian, some variation in Gaelic speech simply does not take on social meaning: One form is just as good as another. This means that individuals are freer to speak differently from one another. 
Thinking about variation from the individual outward rather than from the social inward means thinking about how individuals create unique voices by selecting and combining the linguistic resources available to them. Some of these resources may be relatively codified, shared, and consistent: a school-taught standard variety, for example, or a stylized, out-group representation of a nonstandard variety (Hill 1995, Ronkin \& Karn 1999). Some resources may be identified, by those who draw on them, with the codified, standardized "languages" for which there are official labels, such as "English" or "Spanish"; other resources may be drawn from locally identified "mixed" varieties, such as "Tex-Mex." If the speakers in question use distinct sets of resources in distinct situations, they approximate the "bilingual" of linguistic theory, but a mixed variety may function as a single way of speaking (Heller 1995). Other linguistic resources may be highly idiosyncratic, identified with particular situations or people rather than with groups. What a person may actually be trying to reproduce or reject in a particular situation may be "what my mother would have said," for instance, rather than "English" or "South Midland" or "the way women talk."

Not all speakers have access to the same variety of resources. Dialectologists and sociolinguists have traditionally studied people in relatively homogeneous, relatively isolated settings. The sampling methods of the dialect atlas projects meant that geographically isolated rural communities were over-represented in comparison to cities, and the studies that established the field of variationist sociolinguistics were done in socially isolated inner-city neighborhoods (Labov 1972, Wolfram 1969, Fasold 1972, Trudgill 1974). People in such communities may have a relatively limited range of available ways of speaking and may accordingly sound more like one another, orient to the same set of norms or beliefs about speech, or both. In such communities, individuals may have fewer choices about how to act and who to be; "lifestyle" may be handed down rather than chosen (Giddens 1991). But such communities are less and less typical, and it is increasingly evident that our models need to describe speakers in more mobile, heterogeneous social worlds as well. As Giddens suggests, modern life requires individuals to create coherent self-images "reflexively," by drawing selectively on options provided in the social worlds around them. Tradition no longer necessarily dictates how to act. People often live in multiple social worlds, with moral and ontological options and with more of their experience mediated by print and other media (Giddens 1991:82-85). Modern self-identity, according to Giddens, requires creativity and agency.

Accordingly, sociolinguists need to develop and test models of linguistic variation that are less deterministic than are the traditional ways of explaining accents, dialects, and styles. We need models that accommodate the kind of cultural and linguistic heterogeneity that foregrounds options rather than traditions, models that allow the linguistic individual to be seen as a potential agent of choice rather than a passive, socially constructed vehicle for circulating discourses. In my work with Bean, for example (Johnstone 1995, 1998; Johnstone \& Bean 1997), about what "Texas speech" is and does for people, we are exploring the idea that being from 
Texas, or from the American South, affects how people sound only indirectly, via particular choices (sometimes quite consciously strategic, sometimes not) about what local or regional-sounding speech forms can mean and accomplish. Bean (1993) shows how "professional Texan" Molly Ivins positions herself in her writing via linguistic choices as a Westerner but rejects Southern ways of acting and talking; other Texas women, on the other hand, make a variety of strategic uses of stylized Southern forms (Johnstone 1999).

One consequence of this way of thinking about variation is that it makes the distinction between "social" and "stylistic" variation seem considerably less clear than it once did (Biber \& Finegan 1994, Rickford \& Eckert forthcoming). Stylistic or "register" variation is traditionally defined as relatively strategic adaptation to the situation at hand. When social variation is seen as a relatively automatic result of social facts about speakers, it is easy to differentiate from register variation. But if we see social variation as originating, at least sometimes, in strategic adaptations to situations, then the distinction becomes hard to maintain. This is particuarly clear in cases of obviously performed (Bauman 1977), stylized uses of "social" variants. Natalie Schilling-Estes (1998), for example, describes Okracoke Islanders who exaggerate their own variety in certain key phrases they repeat to tourists and other outsiders. Mary Bucholtz (1999) and Cecilia Cutler (1999) describe uses of African-American sounding speech features by white American youth. "Styling the other" (Rampton 1999) is also the topic of Rampton's (1995) work about "language crossing." Thinking about variation from the perspective of the individual makes it possible to focus on the very beginning of a change, the first time an innovative form is used. This may, Rampton suggests (1998), typically occur in "liminal" situations that call forth linguistic performances.

\section{THE LINGUISTIC INDIVIDUAL AND THE LINGUISTICS OF PARTICULARITY}

Implicit in the work I have described on the heuristic, rhetorical character of textbuilding and interpretation, and on the relationships between individual identity and sociolinguistic variability, is a refocusing of linguistics. It is being increasingly suggested that the questions that define linguistics can be fully answered only with reference to the particular, by recasting questions about social facts and entities as questions about particular speakers and particular interactions, questions about language as questions about discourse, questions about rules and constraints as questions about strategies and resources. Over the past two decades, speakers and utterances have replaced linguistic systems as the object of study for a growing number of linguists. Some of these scholars are identified with interactional sociolinguistics (Gumperz 1982a,b; Tannen 1984, 1989); others are identified with anthropological linguistics (Hymes 1981, Friedrich 1986, Sherzer 1987), conversation analysis (Sacks et al 1974, Goodwin 1981, Atkinson \& Heritage 1984), or corpus linguistics (Sinclair 1991, Stubbs 1996). Many use discourse analysis as 
their primary analytical methodology. These linguists see language as residing in talk. Reluctant to abstract away from our actual experience of languagethe experience of seeing people, not languages, do things and possess linguistic attributes - they ask why actual, situated utterances take the shapes they do, aiming thereby to display the processes by which people create identities and organize social activity. They tend to see language as a byproduct of discourse, rather than the other way around, and the social as an artifact of the individual. As Charles Hockett (1987) puts it, language is a "social system" only to the extent that individual systems overlap. Individual languages are constantly "intercalibrated" in the process of communication, so that "by virtue of these parallels the participants can ordinarily manage to understand one another" (p. 157). "Language" is, then, a myth (Harris 1981), a concept people create when they start thinking about the abstractions they make that enable them to say the same things over again (Love 1990). Linguistic work that takes the phenomenological perspective of the individual studies particular activities and processes rather than abstract social entities: not language but discourse or, as A. L. Becker (1995) puts it, "languaging"; not grammar but "grammaticalization" (Hopper \& Traugott 1993, Hopper 1996), or the process by which phrases and words become bleached and codified over time into grammatical markers as a result of their repeated usefulness in text-building.

Taking the perspective of the individual on language and discourse means shifting to a more rhetorical way of imagining how language works. It means shifting to a way of thinking about communication that incorporates ideas such as strategy, purpose, rhetorical ethos, agency (and hence responsibility), and choice-without, of course, ignoring the many ways in which individuals' options may be limited or sometimes nonexistent. It means imagining other people not only (or not always) as "the creatures of their social relationships," but as their "orchestrators" (Cohen 1994:93). Ethically, it means extending "to cultural 'others' the self consciousness we so value in ourselves" (5).

Taking the perspective of the individual on language also requires a shift to the sort of methodological particularity that Becker (1995) calls "modern philology," in which work in the bottom-up, inside-outward cases-and-interpretations mode (Geertz 1983) supplements work of the more traditional sort. This means "starting with a particular text in context: a conversation, a poem, or any other bit of particular prior text. The rigor comes from the particular case, in describing it robustly and carefully. Formal theories of analysis come and go for [people who work in this mode].... What remains as the unifying discipline is the case in all its particularity" (Becker 1994:163). Becker's "modern philology" requires a linguistic methodology based on close reading. The kind of close attention to real examples of language use that is traditionally the focus of criticism-illuminated by an awareness of the importance of creativity and self expression that supplements our traditional disciplinary awareness of the importance of convention, formulaicity, and rule - can help us to see things about how language works that are usually obscured. What people do when they talk has a great deal to do with knowledge that can be modeled with rules and conventions. It has a great deal to do with the need 
for unambiguous referentiality. Intuitive work and quantitative analyses of large corpora of data have important roles to play. But the linguistics of language cannot achieve explanatory adequacy without a linguistics of the individual speaker.

\section{ACKNOWLEDGMENT}

This essay is dedicated to the memory of my father, Henry W Johnstone $\operatorname{Jr}(1920$ 2000). Whatever intellectual rigor or clarity of exposition is in evidence here, or in my other work, is largely the result of his influence and example.

\section{Visit the Annual Reviews home page at www.AnnualReviews.org}

\section{LITERATURE CITED}

Abu-Lughod L. 1991. Writing against culture. In Recapturing Anthropology, ed. RG Fox, pp. 137-162. Santa Fe, NM: Sch. Am. Res.

Atkinson JM, Heritage J, eds. 1984. Structures of Social Action. Cambridge, UK: Cambridge Univ. Press

Bakhtin MM. 1981 (1953). The Dialogic Imagination. Transl. C Emerson, M Holquist. Austin: Univ. Texas Press (From Russian)

Bakhtin MM. 1986. Speech Genres and Other Late Essays. Transl. VW McGee. Austin: Univ. Texas Press (From Russian)

Bauman R. 1977. Verbal Art as Performance. Rowley, MA: Newbury House

Bean JM. 1993. 'True grit and all the rest': expression of regional and individual identities in Molly Ivins' discourse. J. Southwest. Am. Lit. 19:35-46

Becker AL. 1981. On Emerson on language. In Georgetown University Round Table on Languages and Linguistics 1981, ed. D. Tannen, pp. 1-11. Washington, DC: Georgetown Univ. Press

Becker AL. 1994. Repetition and otherness: an essay. In Repetition in Discourse: Interdisciplinary Perspectives, ed. B Johnstone, 2:162-75. Norwood, NJ: Ablex

Becker AL. 1995. Beyond Translation: Essays Toward a Modern Philology. Ann Arbor: Univ. Mich. Press

Bellah RN, Madsen R, Sullivan WM, Swidler A, Tipton SM. 1985. Habits of the Heart:
Individualism and Commitment in American Life. Berkeley: Univ. Calif. Press

Benveniste É. 1986. Subjectivity in language. In Critical Theory Since 1965, ed. H Adams, L Searle, pp. 728-732. Transl. ME Meek. Tallahassee, Fl: Univ. Press of Florida (From French)

Biber D, Finegan E, eds. 1994. Sociolinguistic Perspectives on Register. New York: Oxford Univ. Press

Bloch M. 1971. Symbols, song, dance and features of articulation. Eur. J. Sociol. 15:55-81

Booth W. 1961. The Rhetoric of Fiction. Chicago: Univ. Chicago Press

Brenneis D. 1986. Shared territory: audience, indirection and meaning. Text 6:339-47

Bucholtz M. 1999. You da man: narrating the racial other in the production of white masculinity. J. Sociolinguist. 3:443-60

Carden G. 1970. A note on conflicting idiolects. Linguist. Inq. 1:281-90

Carr D. 1986. Time, Narrative, and History. Bloomington: Indiana Univ. Press

Carrithers M, Collins S, Lukes S, eds. 1985. The Category of the Person: Anthropology, Philosophy, History. Cambridge, UK: Cambridge Univ. Press

Cherry RD. 1998 (1988). Ethos versus persona: self-representation in written discourse. Writ. Compos. 15:384-410

Chomsky N. 1986. Knowledge of Language. New York: Praeger

Cohen AP. 1993. The future of the self. In 
Humanising the City? Social Contexts of Urban Life at the Turn of the Millennium, ed. AP Cohen, K Fukui, pp. 201-221. Edinburgh: Edinburgh Univ. Press

Cohen AP. 1994. Self Consciousness: An Alternative Anthropology of Identity. London: Routledge

Coulmas F, ed. 1981. Conversational Routine: Explorations in Standardized Communication Situations and Prepatterned Speech. The Hague: Mouton

Craig CG. 1979. Jacaltec: fieldwork in Guatemala. In Languages and Their Speakers, ed. T Shopen, pp. 3-75. Philadelphia: Univ. Penn. Press

Cumming S, Ono T. 1997. Discourse and grammar. In Discourse as Structure and Process, ed. T van Dijk, pp. 112-37. London: Sage

Cutler CA. 1999. Yorkville crossing: white teens, hip hop, and African American English. J. Sociolinguist. 3:428-42

Dorian N. 1994. Varieties of variation in a very small place: social homogeneity, prestige norms, and linguistic variation. Language 70:631-96

Duranti A. 1993. Truth and intentionality: an ethnographic critique. Cult. Anthropol. 8:214-45

Duranti A, Brenneis D. 1986. The audience as co-author. Special Issue Text 6:3

Enos R, Lauer J. 1992. The meaning of 'heuristic' in Aristotle's Rhetoric and its implications for contemporary rhetorical theory. In A Rhetoric of Doing, ed. S Witte, R Cherry, N Nakodate, pp. 79-87. Carbondale: S. Illinois Univ. Press

Fasold R. 1972. Tense Marking in Black English: A Linguistic and Social Analysis. Washington, DC: Cent. Appl. Linguist.

Ferrara K. 1992. The interactive achievement of a sentence: joint productions in therapeutic discourse. Discourse Process. 15:207-28

Fillmore C, Kempler D, Wang WS-Y, eds. 1979. Individual Differences in Language Ability and Language Behavior. New York: Academic

Friedrich P. 1986. The Language Parallax: Lin- guistic Relativism and Poetic Indeterminacy. Austin: Univ. Texas Press

Gal S. 1993. Diversity and contestation in linguistic ideologies: German speakers in Hungary. Lang. Soc. 22:337-59

Geertz C. 1983. Local Knowledge: Further Essays in Interpretive Anthropology. New York: Basic Books

Giddens A. 1991. Modernity and Self-identity. Cambridge, UK: Polity

Goffman E. 1959. The Presentation of Self in Everyday Life. Garden City, NY: Doubleday Anchor Books

Goffman E. 1981. Footing. In Forms of Talk, pp. 124-59. Philadelphia: Univ. Penn. Press

Goodwin C. 1979. The interactive construction of a sentence in natural conversation. In Everyday Language: Studies in Ethnomethodology, ed. G Psathas, pp. 97-121. New York: Irvington

Goodwin C. 1981. Conversational Organization: Interaction Between Speakers and Hearers. New York: Academic

Goodwin J. 1993. Autobiography: The SelfMade Text. New York: Twayne

Greenblatt SJ. 1980. Renaissance SelfFashioning: From More to Shakespeare. Chicago: Univ. Chicago Press

Gumperz JJ. 1982a. Discourse Strategies. Cambridge, UK: Cambridge Univ. Press

Gumperz JJ, ed. 1982b. Language and Social Identity. Cambridge, UK: Cambridge Univ. Press

Hallowell AI. 1955. The self and its behavioral environment. In Culture and Experience, ed. A Hallowell, pp. 75-110. Philadelphia: Univ. Penn. Press

Hannerz U. 1996. Transnational Connections: Culture, People, Places. London: Routledge

Hansen O. 1990. Aesthetic Individualism and Practical Intellect: American Allegory in Emerson, Thoreau, Adams, and James. Princeton, NJ: Princeton Univ. Press

Harris R. 1981. The Language Myth. London: Duckworth

Heller M. 1995. Code-switching and the politics of language. In One Speaker, Two 
Languages: Cross-disciplinary Perspectives on Code-switching, ed. L Milroy, P Muysken, pp. 158-74. Cambridge, UK: Cambridge Univ. Press

Hill J. 1995. Junk Spanish, covert racism and the (leaky) boundary between public and private spheres. Pragmatics 5:197-212

Hill J, Irvine J, eds. 1992. Responsibility and Evidence in Oral Discourse. Cambridge, UK: Cambridge Univ. Press

Hockett CF. 1987. Refurbishing Our Foundations: Elementary Linguistics from an Advanced Point of View. Amsterdam: Benjamins

Holdcroft D. 1991. Saussure: Signs, System, and Arbitrariness. Cambridge, UK: Cambridge Univ. Press

Hopper PJ. 1988. Emergent grammar and the a priori grammar postulate. In Linguistics in Context: Connecting Observation and Understanding, ed. D Tannen, pp. 117-34. Norwood, NJ: Ablex

Hopper PJ. 1996. Some recent trends in grammaticalization. Annu. Rev. Anthropol. 25:217-36

Hopper PJ, Traugott EC. 1993. Grammaticalization. Cambridge, UK: Cambridge Univ. Press

Hudson RA 1980. Sociolinguistics. Cambridge, UK: Cambridge Univ. Press

Humboldt Wv. 1971 (1836). Linguistic Variability and Intellectual Development. Transl. GC Buck, FA Raven. Coral Gables, FL: Univ. Miami Press (From German)

Hymes D. 1974. Foundations in Sociolinguistics: An Ethnographic Approach. Philadephia: Univ. Penn. Press

Hymes D. 1979. Sapir, competence, voices. See Fillmore et al. 1979, pp. 33-45

Hymes D. 1981. In Vain I Tried to Tell You: Essays in Native American Ethnopoetics. Philadelphia: Univ. Penn. Press

Johnstone B. 1995. Sociolinguistic resources, individual identities and the public speech styles of Texas women. J. Linguist. Anthropol. 5:1-20

Johnstone B. 1997. Social characteristics and self-expression in narrative. In Oral Versions of Personal Experience: Three Decades of Narrative Analysis, ed. MGW Bamberg. Special Issue. J. Narrat. Life Hist. 7:315-20

Johnstone B. 1998. "Sounding country" in urbanizing Texas: private speech in public discourse. Mich. Discuss. Anthropol. 13:153-64

Johnstone B. 1999. Uses of Southern speech by contemporary Texas women. J. Sociolinguist. 3:505-22

Johnstone B, Bean JM. 1997. Self-expression and linguistic variation. Lang. Soc. 26:22146

Kripke S. 1982. Wittgenstein on Rules and Private Language. Cambridge, MA: Harvard Univ. Press

Kroch A, Small C. 1978. Grammatical ideology and its effect on speech. In Linguistic Variation: Methods and Models, ed. D Sankoff, pp. 45-55. New York: Academic

Kroskrity PV, Schieffelin BB, Woolard KA. 1992. Language Ideologies. Special Issue Pragmatics 2(3):235-453

Labov W. 1963. The social motivation of a sound change. Word 19:237-309

Labov W. 1972. Sociolinguistic Patterns. Philadelphia: Univ. Penn. Press

Labov W. 1994. Principles of Linguistic Change: Internal Factors. New York: Blackwell

Leech GN. 1983. Principles of Pragmatics. London: Longman

LePage RB. 1994. The notion of 'linguistic system' revisited. Int. J. Sociol. Lang. 109:10920

LePage RB, Tabouret-Keller A. 1985. Acts of Identity: Creole-based Approaches to Language and Ethnicity. Cambridge, UK: Cambridge Univ. Press

Levinson SC. 1983. Pragmatics. Cambridge, UK: Cambridge Univ. Press

Linde C. 1993. Life Stories: The Creation of Coherence. Oxford, UK: Oxford Univ. Press Love N. 1990. The locus of language in a redefined linguistics. In Redefining Linguistics, ed. HG Davis, TJ Taylor, pp. 53-117. London: Routledge 
Mauss M. 1985 (1938). A category of the human mind: the notion of person, the notion of self. See Carrithers et al. 1985, pp. 1-25

Milroy J. 1992. Linguistic Variation and Change. Oxford UK: Blackwell

Milroy L. 1987. Language and Social Networks. Oxford, UK: Blackwell. 2nd ed.

Milroy L. 1999. Sociolinguistic patterns and attitudes to language: Can we fit the pieces of the jigsaw together? Presented at Conf. Methods Sociolinguist. in Honor of Ronald KS Macaulay, Pitzer College, Claremont, CA, November 12

Morris C. 1987. The Discovery of the Individual, 1050-1200. Toronto/Buffalo, NY: Univ. Toronto Press

Ochs D. 1969. Aristotle's concept of formal topics. Speech Monogr. 36:412-25

Ochs D. 1983. Cicero's topica: a process $\rightarrow_{\mathrm{W}}$ of invention. In Explorations in Rhetoric: Studies in Honor of Douglas Ehninger, ed. R McKerrow, pp. 107-118. Glenview, IL: Scott

Ochs E, Schegloff E, Thompson SA, eds. 1996. Interaction and Grammar. New York: Cambridge Univ. Press

Ochs E, Schieffelin BB, Platt M. 1979. Propositions across utterances and speakers. In Developmental Pragmatics, ed. E Ochs, BB Schieffelin, pp. 251-68. New York: Academic

Paul H. 1889. Principles of the History of Language. Transl. HA Strong. New York: Macmillan (From German)

Rampton B. 1995. Crossing: Language and Ethnicity Among Adolescents. London: Longman

Rampton B. 1998. Language crossing an $\rightarrow 1 e$ redefinition of reality. In Code-Switching in Conversation, ed. P Auer, pp. 290-320. London: Routledge

Rampton B, ed. 1999. Styling the "Other." $\rightarrow$ cial Issue $J$. Sociolinguist. 3:421-556

Rickford J, Eckert P, eds. Forthcoming. Style and Variation. Cambridge, UK/New York: Cambridge Univ. Press

Robins RH. 1976. A Short History of Linguistics. London: Longman. 2nd ed.
Ronkin M, Karn HE. 1999. Mock Ebonics: linguistic racism in parodies of Ebonics on the internet. J. Sociolinguist. 3:360-80

Rosaldo MZ. 1984. Toward an anthropology of self and feeling. In Culture Theory: Essays on Mind, Self, and Emotion, ed. RA Shweder, RA LeVine, pp. 137-57. Cambridge, UK: Cambridge Univ. Press

Rosen L, ed. 1995. Other Intentions: Cultural Contexts and the Attribution of Inner States. Santa Fe, NM: Sch. Am. Res.

Ross JR. 1979. Where's English? See Fillmore et al. 1979, pp. 127-63

Ross WD, ed. 1924. The Works of Aristotle. Vol. XI. Rhetorica. Transl. W Rhys Roberts. Oxford, UK: Clarendon Press (From Greek)

Sacks H, Schegloff EA, Jefferson G. 1974. A simplest systematics for the organization of turn taking for conversation. Language 50:696-735

Sankoff D, Cedergren HJ, Kemp W, Thibault P, Vincent D. 1989. Montreal French: language, class, and ideology. In Language Change and Variation, ed. $\mathrm{R} \mathrm{Fa-}$ sold, D Schiffrin, pp. 107-18. Amsterdam/Philadelphia, PA: Benjamins

Sapir E. 1921. Language. New York: Harcourt Brace

Sapir E. 1949. Selected Writings of Edward Sapir in Language, Culture and Personality. Berkeley: Univ. Calif. Press

Saussure F. 1966 (1916). A Course in General Linguistics. Transl. W Baskin. New York: McGraw Hill (From French)

Schilling-Estes N. 1998. Investigating "selfconscious" speech: the performance register in Ocracoke English. Lang. Soc. 27:5383

Sherzer J. 1987. A discourse-centered approach to language and culture. Am. Anthropol. 89:295-305

Silverstein M. 1979. Language structure and linguistic ideology. In The Elements: A Parasession on Linguistic Units and Levels, ed. P Clyne, WF Hanks, C Hofbauer, pp. 193-247. Chicago: Chicago Linguist. Soc. 
Sinclair JM. 1991. Corpus, Concordance, Collocation. Oxford, UK: Oxford Univ. Press

Sperber D, Wilson D. 1986. Relevance: Communication and Cognition. Cambridge, MA: Harvard Univ. Press

Stubbs M. 1996. Text and Corpus Analysis: Computer-Assisted Studies of Language and Culture. Oxford, UK: Blackwell

Tannen D. 1984. Conversational Style: Analyzing Talk Among Friends. Norwood, NJ: Ablex

Tannen D. 1987. Repetition in conversation as spontaneous formulaicity. Text 7:215-43

Tannen D. 1989. Talking Voices: Repeti $\rightarrow .$. , Dialogue, and Imagery in Conversational Discourse. Cambridge, UK: Cambridge Univ. Press

Taylor C. 1989. Sources of the Self: The Making of Modern Identity. Cambridge, MA: Harvard Univ. Press

Trudgill P. 1974. The Social Differentiation of English in Norwich. Cambridge, UK: Cambridge Univ. Press

Vossler K. 1904. Positivismus und Idealismus in der Sprachwissenschaft. Heidelberg: C Winter

Wolfram W. 1969. A Sociolinguistic Description of Detroit Negro Speech. Washington, DC: Cent. Appl. Linguist.

Woolard KA, Schieffelin BB. 1994. Language ideology. Annu. Rev. Anthropol. 23:55-82

Young RE. 1987. Some recent developments in rhetorical invention. In Teaching Composition: 12 Bibliographic Essays, ed. G Tate, pp. 1-38. Fort Worth: Texas Christian Univ. Press 